\title{
ESTUDOS DOS FATORES DE RISCO PRÉ-OPERATÓRIOS PARA BACTERIOBILIA EM DOENTES PORTADORES DE COLECISTITE AGUDA CALCULOSA
}

\author{
M.M. Linhares, V. Paiva, A. Castelo Filho, L.C.S. Granero, C.A. Pereira, \\ A.M.O. Machado, A. Goldenberg, *D. Matos \\ DisciplinadeGastroenterologiaCirúrgica, UniversidadeFederaldeSãoPaulo, \\ Escola PaulistadeMedicina,SãoPaulo,Brasil.
}

RESUMO - OBjETIVO. Determinar uma associação entre o quadro clínico pré-operatório e os resultados das culturas de bile e da parece vesicular.

CAsuistica e Métodos. Foram estudadas 28 variáveis considerando-se história clínica, exame físico e investigação laboratorial em 38 doentes portadores de colecistite aguda calculosa, submetidos à cirurgia de urgência. Este estudo prospectivo foi realizado em 19 meses, entre novembro de 1995 a maio de 1997. Foram realizadas culturas para agentes anaeróbios e aeróbios, em três diferentes meios de cultura (BACTEC 9240, BHI e HEMOBAC).

REsULTADOs. Foram isoladas bactérias em pelo menos um meio de cultura em $68,2 \%$ dos doentes. Pela análise univariada, foram identificadas cinco variáveis pré-operatórias como preditivas de bacteriobilia: idade acima de 55 anos, temperatura diferencial axiloretal maior do que $0,4^{\circ} \mathrm{C}$, leucocitose acima de $12000 \mathrm{cels} / \mathrm{mm}^{3}$, neutrofilia acima de $75 \%$ e neutrófilos bastonetes acima de $4 \%$. Devido ao pequeno tamanho da amostra, não pôde ser observada significância estatística por regressão logística, embora pudesse ser observada em $98 \%$ uma tendência para determinação pré-operatória dos indivíduos com cultura positiva por meio do modelo baseado na idade e porcentagem de neutrófilos bastonetes. Pela análise em conjunto dos fatores preditivos, pôde-se observar que doentes com mais de um fator preditivo têm uma possibilidade significantemente maior para cultura positiva, quando comparado com aqueles com fator preditivo de bacteriobilia.

Conclusáa. Conclui-se, portanto, que pela utilização de dados facilmente disponiveis em doentes com colecistite aguda calculosa, a bacteriobilia pode ser previsivel no pré-operatório,.

Unitermos: Bacteriobilia. Colecistite Aguda. Fatores de Risco.

\section{INTRODUÇÃo}

Apesar de já ter sido demonstrado que a maioria dos doentes com colecistite aguda não apresenta crescimento de bactérias na bile', a colecistite infecciosa constituiu-se em um dogma do passado e aceita até a quarta década deste século, quando, devido ao progresso das técnicas bacteriológicas, foi observado que a origem bacteriana da colecistite aguda não era tão absoluta quanto se supunha e, seguramente, intervinham outros fatores coadjuvantes, que eram importantes na gênese desta doença ${ }^{2,3,4}$.

Vários estudos encontraram associação

${ }^{*}$ Correspondência: R. Edison, 278-apto. 61-Campo Belo Cep:04618-031-SãoPaulo-SP positiva entre a presença de bactéria na bile e alguns dados clínicos pré-operatórios, caracterizando como fatores de risco para a bacteriobilia as seguintes variáveis: idade maior que sessenta anos ${ }^{5,6}$, idade maior que setenta $a^{7}{ }^{7-11}$, história prévia de colecistite aguda ${ }^{5}$, icterícia obstrutiva e colecistite aguda $7,8,10$, coledocolitíase, diabetes melito e vesícula biliar não funcionante no colecistograma oral ${ }^{10}$. Entretanto, ao selecionar, exclusivamente, estudos prospectivos realizados em uma população específica de pacientes submetidos à colecistectomia por colecistite aguda, observam-se cinco fatores preditivos de bacteriobilia com significância estatística: idade dos doentes ${ }^{12}$, doenças associadas ${ }^{13}$, temperatura corpórea ${ }^{12,14-16}$, níveis séricos de bilirrubina total| e percentagem de neutrófilos ${ }^{13}$. Apenas um trabalho avaliou a presença de fatores preditivos de bacteriobilia por meio da análise multivariada discriminante, formulando uma equação matemática, baseada na contagem de leucócitos, na percentagem de neutrófilos, na bilirrubina total e na temperatura axilar ${ }^{17}$.

Os trabalhos acima citados diferem no método em relação aos fatores de inclusão e exclusão, ao tempo decorrido do diagnóstico à operação, ao número de variáveis avaliadas, à técnica e aos meios de cultura empregados e à análise estatística dos dados. Por estes fatos, propusemos realizar estudo prospectivo em uma amostra homogênea, especificamente em doentes portadores de colecistite aguda, submetidos à colecistectomia precoce e com confirmação histológica para tentar definir e 
quantificar os fatores pré-operatórios preditivos de bacteriobilia, utilizando métodos de cultivos, de detecção e de identificação bacterianos automatizados, bem como empregando uma análise estatística multivariada.

\section{Métodos e Casuística}

Foram estudados, de forma prospectiva, 38 doentes submetidos à colecistectomia de urgência, por colecistite aguda calculosa, no Pronto Socorro do Hospital São Paulo, num período de 19 meses, compreendido entre Outubro de 1995 a Maio de 1997. Foram incluídos doentes portadores de colecistite aguda calculosa submetidos à colecistectomia dentro de 24hs da admissão e que concordaram em participar deste protocolo. Excluíram-se os doentes submetidos à terapêutica antimicrobiana nos últimos sete dias, aqueles portadores de processo infeccioso nos últimos 30 dias, assim como aqueles sem comprovação histológica de colecistite aguda. $\mathrm{O}$ exame considerado padrão para o diagnóstico de colecistite aguda foi o exame microscópico, mostrando a presença de infiltrado polimorfonuclear granulocítico na parede vesicular $^{18}$.

A avaliação clínica foi realizada, sempre, por uma única equipe médica, sendo selecionadas as seguintes variáveis da história clínica: idade, sexo, duração dos sintomas, náuseas, vômitos, febre, calafrios, história pregressa de cólicas biliares; do exame físico: icterícia, temperatura axilar, temperatura retal, diferença de temperatura axiloretal, tumor inflamatório palpável no ponto cístico, descompressão brusca dolorosa ao nível do hipocôndrio direito, parada da inspiração profunda durante palpação do ponto cístico (sinal de Murphy); e dos exames laboratoriais: dosagem de glicose, creatinina, bilirrubina total, bilirrubina direta, bilirrubina indireta, transaminase glutâmico oxalacética (TGO), transaminase glutâmico pirúvica (TGP), amilase, albumina, contagem de leucócitos, percentagens de bastonetes, segmentados e de neutrófilos.

No ato operatório, após a aspiração da bile da vesícula, procedeu-se sua imediata inoculação nos meios de cultura Bactec plus $9240^{\circledR}$ para aeróbios e anaeróbios, tripsicaseína de soja $\left(H_{e m o b a c}{ }^{\circledR}\right.$ e e meio BHI caldo. Finalmente, um fragmento do infundíbulo vesicular de um centímetro quadrado foi excisado em condições assépticas e colocado em frasco com tripsicasína de soja $\left(\right.$ Transbac $^{\circledR}$ ). O sistema Bactec plus $9240^{\circledR}$ detectou automaticamente o crescimento bacteriano nos frascos Bactec e nos demais meios de cultura a detecção foi realizada pela técnica convencional. Todas as bactérias aeróbias foram identificadas pelo Sistema MicroScan, utilizando o aparelho WalkAway-40 ${ }^{\circledR}$. Oequipamento efetuou automaticamente a identificação das bactérias e os antibiogramas correspondentes. Considerou-se bacteriobilia a presença de bactérias nabileouna parede vesicular, confirmada por meio de isolamento em, pelo menos, um dos meios de culturas utilizados ${ }^{14}$.

Para fins de análise, os doentes foram divididos em grupos I e II, respectivamente, de acordo com a presença ou ausência de bactérias nas culturas de bile e/ou da parede vesicular. Em todos os testes estatísticos utilizados foram consideradas como significantes os resultados com nível descritivo inferior a $5 \%(p<0,05)$. Foram considerados como fatores preditivos de bacteriobilia as variáveis que apresentaram significância estatística ao serem confrontadas com a presença ou ausência de bacteriobilia e dicotomizadas pelos respectivos pontos de corte. Utilizou-se o teste exato de Fisher para a análise das variáveis qualitativas ${ }^{19,20}$. Nas variáveis quantitativas contínuas, realizou-se a comparação das médias de cada variável em relação aos grupos I e II, utilizando-se o teste de Mann-Whitney ${ }^{19}$. Nas variáveis quantitativas contínuas, cujos re- sultados das médias diferiram de forma estatisticamente significante, empregou-se o cálculo da área sob a curva ROC (receiver operator characteristic) $)^{21}$ para determinar o ponto de corte de cada variável que otimizava os valores da sensibilidade e da especificidade da respectiva variável, quanto ao seu valor preditivo de bacteriobilia. A seguir, utilizou-se o teste exato de Fisher para comparar os grupos I e I| quanto à proporção de pacientes com ou sem o fator de risco (determinado por cada variável quantitativa, categorizada pelo ponto de corte obtido através da curva ROC). As variáveis que apresentaram diferença significante entre os dois grupos foram selecionadas para compor uma análise de regressão logística múltipla, utilizando-se o método stepwise. As análises estatísticas foram realizadas em computador IBM-compatível, utilizando-se o pacote estatístico BMDP versão 5.0 .

\section{Resultados}

A média de idade dos doentes foi de 50,2 anos, variando de 24 a 84 anos. Em relação ao sexo, 25 doentes $(65,8 \%)$ eram do sexo feminino e 13 doentes (34,2\%) eram do sexo masculino. Em 26 (68,4\%) dos 38 doentes estudados, observou-se crescimento bacteriano em, pelo menos, um meio de cultura utilizado (GRUPO I). Observaram-se culturas negativas em 12 (31,6\%) doentes (GRUPO II). O número de doentes com culturas positivas foi 22 (57\%), 17 (44\%), 19 (50\%) e 24 (63\%), respectivamente, no BACTEC PLUS $9240^{\circledR}, \mathrm{BHI}, \mathrm{HEMOBAC}{ }^{\circledR}$ e cultura do fragmento da parede da vesícula biliar. Ao comparar-se a positividade nos quatro meios de cultura para bile e para a parede da vesícula biliar utilizando-se o teste $G$ de Cochran, observou-se uma diferença estatisticamente significante $(p=0,0 \mid 7)$; no entanto, na análise através de partições, quando os re- 
sultados de cada meio de cultura foram comparados entre si, apenas o meio $\mathrm{BH}$ apresentou positividade significantemente menor em relação às culturas de parede da vesícula biliar $(p=0,008)$. Não se observaram diferenças significantes entre os métodos de cultura de bile.

Os diversos tipos de bactérias isoladas em 9l amostras de bile e da parede da vesícula biliar de 38 doentes portadores de colecistite aguda calculosa são apresentados na tabela I.

Não foram observadas diferenças significantes entre os grupos I e $\mid l$ em relação ao sexo $(p=0,48)$; presença dos sintomas préoperatórios: febre $(p=0,47)$, calafrios $(p=0,45)$, náuseas $(p=1,00)$, vômitos $(p=1,00)$, cólicas biliares $(p=0,15)$; e sinais do exame físico abdominal: icterícia $(p=0,39)$, massa palpável $(p=0,46)$, descompressão brusca dolorosa $(p=0,48)$, e sinal de Murphy $(p=1,00)$. A tabela 2 mostra as médias das variáveis contínuas, bem como os resultados dos testes comparativos entre os dois grupos. Não foi verificada a temperatura retal em cinco doentes e, consequentemente, todos os testes estatísticos que envolveram os dados da temperatura retal e da diferença de temperatura axilo-retal, somente foram calculados em uma amostra de 33 doentes.

As variáveis cujos resultados foram significantes ao aplicarmos o teste exato de Fisher, utilizando como ponto de corte os valores otimizados obtidos através da curva ROC, são apresentados na tabela 3. As variáveis temperatura retal e bilirrubina direta não apresentaram resultados significantemente diferentes entre os grupos com bactérias presentes e ausentes.

$\mathrm{Na}$ tabela 4 observa-se a distribuição dos doentes quanto ao número de fatores preditivos significantes encontrados a partir da análise univariada, quando considerados, em conjunto, em termos de "fatores de risco" para bacteriobilia e estratificados pe-

Tabela I - Distribuição dos tipos de bactérias identificadas nas culturas de bile e da parede da vesícula em 38 doentes de colecistie aguda calculosa.

\begin{tabular}{llcc}
\hline GRAM & BACTÉRIAS & N & $\%$ \\
& Sstreotococos alfa hemolíticos & 10 & 11.0 \\
Positivos & Streptococcus faecalis & 9 & 10.0 \\
& Staphvlococcus sp. & 9 & 10.0 \\
& outros & 4 & 4.0 \\
& Total & 32 & 35,0 \\
Negativos & Escherichia coli & 20 & 22.0 \\
& Klebsiella sp. & 20 & 22.0 \\
& Enterobacter sp. & 15 & 17.0 \\
Total de Bactérias & Salmonemma sp. & 4 & 4.0 \\
\hline
\end{tabular}

Tabela 2 - Distribuição das médias das variáveis quantitativas e resultados dos testes comparativos entre os dois grupos.

\section{VARIÁVEIS}

Idade (anos)

Dur. sintomas (h)

Temp. $\operatorname{axilar}\left({ }^{\circ} \mathrm{C}\right)$

Temp. retal $\left({ }^{\circ} \mathrm{C}\right)$

Dif. axilo-retal

Glicemia (mg/dl)

Bilirrubina total $(\mathrm{mg} / \mathrm{dl})$

Bilirrubina direta $(\mathrm{mg} / \mathrm{dl})$

Bilirrubina indireta $(\mathrm{mg} / \mathrm{dl})$

TGO $(\mu / l)$

TGP $(\mu / l)$

Amilase $(\mu / l)$

Creatinina (mg/dl)

Albumina (g/dl)

Leucócitos $\left(\mathrm{L} / \mathrm{mm}^{3}\right)$

Bastonetes (\%)

Segmentados (\%)

Neutrófilos (\%)

\section{MÉDIAS DOS GRUPOS}

I II

54,80

85,69

36,97

37,86

0,85

130,12

1,37

0,67

0,71

59,61

66,03

136,95

I,04

4,15

$|5.5| \mid$

6,07

76,78

83,05
40,25

121,25

36,87

37,37

0,48

102,09

1,23

0,65

0,56

59,91

66,25

$103,9 \mid$

0,74

4,35

11.683

2,08

74,16

76,33

p(MANN-WHITNEY)

los resultados das culturas. São, também, apresentados os valores preditivos desta análise.

$\mathrm{Na}$ tabela 5 encontram-se apresentadas as variáveis idade e percentagem de bastonetes, consideradas mais importantes no modelo da regressão logística, com seus respectivos odds ratio e intervalos de confiança.

As probabilidades estimadas de bacte- 
riobilia obtidas pelo do modelo estatístico da regressão logística nas diversas combinações de resultados dos fatores idade e percentagem de bastonetes são apresentados na tabela 6.

\section{Discussão}

É bem conhecido que a bactéria não é a causa inicial da colecistite aguda calculosa, podendo estar ausente na metade dos doentes $^{8,22,16}$; quando presente, no entanto, parece estar associada a maior gravidade ${ }^{12,23,24}$, maior permanência hospitalar ${ }^{24}$, maior morbidade ${ }^{25}$ e a maior mortalidade ${ }^{4}$. Foi descrito em estudos prévios um maior componente tóxico nos doentes com colecistite aguda, que apresentavam bactérias na bile, em comparação com aqueles sem bacteriobilia ${ }^{16,26}$. Estes resultados estão de acordo com as nossas observações na prática clínica, em que notamos não ser a colecistite aguda uma doença uniforme. Enquanto alguns doentes parecem apresentar um maior componente tóxico, associado à febre alta e a calafrios, outros apresentam um quadro clínico que se assemelha ao de um processo puramente inflamatório, predominando os sintomas dolorosos. Estudo prévio mostrou que o julgamento baseado apenas na observação clínica não é suficientemente acurado como guia da presença de bactéria na bile ${ }^{27}$, portanto, a obtenção de um modelo estatístico eficaz que consiga diferenciar, ainda no período préoperatório, estes dois grupos de doentes, pode oferecer ao cirurgião mais um subsídio para o emprego racional dos antimicrobianos, de modo a se obter uma melhor relação custo-benefício no seu emprego.

Em levantamento de 42 pesquisas, estudando-se 2.648 doentes com colecistite aguda, encontrou-se média de $52 \%$ de bacteriobilia, variando de 33,3 a $100 \%{ }^{13}$. Neste estudo, observou-se percentagem de bactérias na bile e/ou na parede vesicular em $68,4 \%$ dos doentes. Acredita-se que

Tabela 3 - Distribuição dos doentes dos grupos I e II de acordo com a idade, diferença de temperatura axilo-retal, contagem de leucócitos, percentagens de bastonetes e de neutrófilos e valores preditivos de bacteriobilia.

\section{VARIÁVEIS}

Idade (anos)

$\geq 55$

$<55$

Dif. temp. axilo-retal

$\geq 0,4$

$<0,4$

Leucócitos

$\geq 12.000$

$<12.000$

Bastonetes (\%)

$\geq 4$

$<4$

Neutrófilos (\%)

$\geq 75$

21

$<75$

\section{$\mathrm{p}=$ significa estatística \\ $\mathbf{S}=$ sensibilidade \\ $\mathbf{E}=$ especificidade}

4

GRUPOS
I II

14

12

19

6

$S=0,54$

II

$p=0,03$

$\mathrm{S}=0,83$

4

$E=0,60$

$\mathrm{VPP}=0,83$

VPN $=0,60$

$A=0,76$

$\mathrm{p}=0,03$

$S=0,73$

$E=0,67$

$\mathrm{VPP}=0,83$

$\mathrm{VPN}=0,53$

$A=0,7$ |

$p=0,03$

$s=0,46$

$\mathrm{E}=0,92$

$\mathrm{VPP}=0,92$

$\mathrm{VPN}=0,44$

$A=0,60$

$\mathrm{p}=0,03$

$S=0,81$

$E=0,58$

$\mathrm{VPP}=0,81$

$\mathrm{VPN}=0,58$

$A=0,74$ esta prevalência se deva à criteriosa seleção de doentes, incluindo somente aqueles com confirmação histológica de colecistite aguda e à indicação precoce do procedimento cirúrgico, excluindo-se aqueles que fizeram uso prévio de antimicrobianos.

Concordando com os resultados de vários estudos anteriores ${ }^{16,31,32}$, observou- se, nesta casuística, predomínio de bactérias da flora intestinal no líquido vesicular e/ou na parede da vesícula, com prevalência dos germes Gram negativos, principalmente dos gêneros Escherichia sp., Klebsiella sp. e Enterobacter sp., os quais foram responsáveis por $60,4 \%$ das bactérias isoladas.

Os resultados deste estudo mostram 
diferença significante entre os pacientes portadores e não-portadores de bacteriobilia; estas diferenças puderam ser observadas já na admissão dos pacientes ao hospital, através dos dados da história clínica, do exame físico e dos resultados de exames laboratoriais rotineiramente realizados no período pré-operatório de doentes com colecistite aguda. Os fatores pré-operatórios que apresentaram diferença significante entre os dois grupos estudados foram: idade, diferença de temperatura axilo-retal, número de leucócitos, percentagem de bastonetes e percentagem de neutrófilos.

Em estudos prévios que avaliaram a bacteriobilia em colecistite aguda, a média de idade dos doentes variou entre 45 e 62,9 anos $6,13,14,16,17,33$, estando de acordo com a média de idade de 50,2 anos obtida neste estudo. Conforme citações adiante, a associação do fator idade à presença de bacteriobilia está bem estabelecida. Entretanto, observa-se ampla variação nos critérios de definição usados para avaliar esta associação. Enquanto alguns estudos apenas relataram maior freqüência de bacteriobilia em pacientes mais idosos ${ }^{5}$, outros observaram diferenças na média das idades dos grupos com bactérias presentes e ausentes na bile e/ou na parede vesiculart,26 e, finalmente, outros estudos definiram um valor de idade, o qual foi usado como ponto de corte, e que melhor separou os grupos quanto à presença ou ausência de bactérias ${ }^{6-9,11,22,32}$. Diferentemente dos estudos anteriores, que calcularam o ponto de corte da idade de uma forma aleatória ou baseada em relatos prévios da literatura, neste estudo utilizouse o cálculo da área sob a curva ROC para obter o ponto de corte que melhor separava os grupos I e || quanto à idade, otimizando aquele cálculo, de modo a apresentar maior sensibilidade e maior especificidade da variável quanto ao seu potencial valor preditivo isoladamente. Deste modo, dos I 5 pacientes com mais de 55 anos, apenas

Tabela 4 - Distribuição dos doentes quanto ao número de fatores preditivos estratificados pelos resultados das culturas e seus valores preditivos de bacteriobilia

\begin{tabular}{|c|c|c|c|}
\hline \multirow{2}{*}{$\begin{array}{l}N^{0} \text { DE FATORES } \\
\text { PREDITIVOS }\end{array}$} & \multicolumn{2}{|c|}{ CULTURAS } & \multirow{2}{*}{$\begin{array}{l}\text { VALORES } \\
\text { PREDITIVOS } \\
\quad p(\text { Fisher })=0,021\end{array}$} \\
\hline & POSITIVAS & NEGATIVAS & \\
\hline Oal & | & 4 & $\begin{array}{l}S=84 \% \\
E=80 \% \\
V P P=96 \%\end{array}$ \\
\hline 2 a 5 & 22 & 6 & $\begin{array}{l}\mathrm{VPN}=40 \% \\
A=79 \%\end{array}$ \\
\hline
\end{tabular}

$\begin{array}{ll}\mathrm{p}=\text { significância estatística } & \mathrm{VPP}=\text { valor preditivo positivo } \\ \mathrm{S}=\text { sensibilidade } & \mathrm{VPN}=\text { valor preditivo negativo } \\ \mathrm{E}=\text { especificidade } & \mathrm{A}=\text { acurácia }\end{array}$

Tabela 5 - Estimativas para os odds-ratio e seus respectivos intervalos de confiança de $95 \%$ obtidas através do modelo de regressão logística múltipla para as variáveis idade e número de bastonetes.

\begin{tabular}{lccc}
\hline VARIÁVEIS & ODDS RATIO & IC DE 95\% & P \\
Idade & 9,52 & $0,93-98,03$ & 0,002 \\
Bastonetes (\%) & 6,45 & $0,60-68,96$ & 0,22 \\
\hline
\end{tabular}

Tabela 6 - Probabilidades estimadas de bacteriobilia, segundo a análise da regressão logística múltipla das variáveis idade e percentual de bastonetes

\begin{tabular}{llcc}
\hline & & \multicolumn{3}{c}{ BASTONETES (\%) } \\
\cline { 3 - 4 } & & $\geq 4$ & $<4$ \\
Idade & $\geq 55$ anos & 0,98 & 0,88 \\
(anos) & $<55$ anos & 0,82 & 0,42 \\
\hline
\end{tabular}

um apresentou cultura negativa (6,6\%), em contraste com 23 doentes com idade inferior a este ponto de corte. Em I I pacientes $(47,8 \%)$ não se observou bacteriobilia. Portanto, a idade maior que 55 anos como fator isolado apresentou alta especificidade (92\%) e alto valor preditivo positivo (93\%).

A presença de febre em pacientes com colecistite aguda é achado comum, mas pode estar ausente em percentagens variáveis de pacientes ${ }^{34,35}$. Quando presente em doentes sem complicações, ela é geralmente menor que $38,3^{\circ} \mathrm{C}$ sendo que o achado de temperaturas maiores deve aumentar a suspeita de complicações ${ }^{36}$. Alguns estudos em pacientes submetidos a cirurgia por colecistite aguda mostraram associação significante entre a elevação da temperatura corpórea e a presença de bactérias na

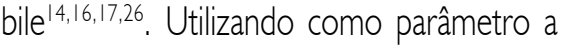
temperatura retal na admissão ao hospital, Watson ${ }^{26}$ observou que as médias das temperaturas nos grupos com e sem bacteriobilia eram, respectivamente, $38,3^{\circ} \mathrm{C}$ e $37,5^{\circ} \mathrm{C}$. Nesta casuística, observou-se diferença significante entre os dois grupos estudados, ao comparar as médias das temperaturas retais; no entanto, os valores das médias foram menores neste estudo (respectivamente $37,9^{\circ} \mathrm{C}$ e $37,4^{\circ} \mathrm{C}$ ). Ao analisar o 
fator temperatura retal isoladamente com base no ponto de corte, esta variável não se comportou como fator preditivo de bacteriobilia. Não foram encontrados, na literatura, dados referentes à análise da diferença de temperatura axilar e retal como fator preditivo de bacteriobilia. Neste estudo, as médias destas diferenças, nos grupos I e II, foram, respectivamente, 0,85 e $0,48^{\circ} \mathrm{C}(\mathrm{p}$ $=0,02)$ e, entre os fatores relacionados com a temperatura corpórea, a diferença axilo-retal foi o único fator que se comportou como preditivo de bacteriobilia.

Em estudos de pacientes com colecistite aguda, observou-se variação na média dos valores da bilirrubina sérica de 19,5 a $4 \mathrm{lmol} / /$ ( I , I a 2,4 mg/dl) e de 13,7 a 19 $\mathrm{mMol} / \mathrm{l}(0,8 \mathrm{a} \mathrm{l}, \mathrm{I} \mathrm{mg} / \mathrm{dl})$, respectivamente, nos grupos com e sem bactérias na bile ${ }^{16,17}$. Neste estudo, nem a bilirrubina total, nem suas frações, independentemente, comportaram-se como fatores preditivos de bacteriobilia.

O pequeno número de publicações que avaliaram e relataram a associação de leucocitose com bacteriobilia apresenta resultados conflitantes. Enquanto alguns autores não conseguiram demonstrar esta associação ${ }^{13,26}$, outros obtiveram valores médios de leucócitos significantemente maiores no grupo com crescimento bacteriano que em doentes sem bactérias na bile ${ }^{16,17}$. Corroborando com estas duas últimas publicações, observaram-se, neste estudo, diferenças significantes das médias dos leucócitos nos grupos I e II. Utilizando o ponto de corte de $12.000 \mathrm{~L} / \mathrm{mm} 3$, verificou-se que em 23 pacientes com leucócitos acima deste valor, 19 (82,6\%) apresentaram culturas positivas em comparação aos 15 doentes com leucócitos menores que $12.000 \mathrm{~L} / \mathrm{mm} 3$, em que $7(46,7 \%)$ apresentaram culturas positivas $(p=0,03)$. Portanto, a variável do número de leucócitos comportou-se isoladamente como fator preditivo de bacteriobilia.
Kobata $^{13}$ e Farinon ${ }^{17}$ demonstraram a importância do fator percentagem de neutrófilos como indicador da presença de bacteriobilia; ambos obtiveram resultados significantemente diferentes entre os grupos com e sem bactérias na bile, tendo, como valores médios de neutrófilos, respectivamente, 84,7 e $77,0 \%{ }^{13}$ e 77,4 e $60,6 \%{ }^{17}$. Nesta casuística, corroborando os estudos prévios, observou-se que os grupos I e II, diferiram significantemente em termos de média, para a variável percentagem de neutrófilos quando confrontada com a presença ou a ausência de bactérias na bile e/ou na parede vesicular. Quando se avaliou o valor do ponto de corte de $75 \%$, obtido por meio do emprego da curva ROC, a variável percentagem de neutrófilos caracterizou-se como um fator preditivo de bacteriobilia, com acurácia de 74\%.

Não foram encontrados estudos que demonstrassem a percentagem de bastonetes como fator preditivo de bacteriobilia. Conhecendo-se a relação causa-efeito das infecções bacterianas com o desvio para a esquerda dos leucócitos e, portanto, com uma maior percentagem de células brancas no sangue periférico, levantou-se a hipótese de haver, também, uma associação da presença de bacteriobilia com uma maior percentagem de bastonetes. Nesta casuística, tanto em termos de média, quanto utilizando-se o ponto de corte, a percentagem de bastonetes comportou-se como fator associado e preditivo de bacteriobilia. Esta variável, isoladamente, apresentou alta especificidade (92\%) e valor preditivo positivo aceitável (92\%).

Ao analisar a possibilidade de prever o resultado das culturas de bile de pacientes com colecistite aguda, Thompson et al. ${ }^{16}$ observaram que nenhuma variável estudada comportou-se acuradamente como um fator preditivo de bacteriobilia; no entanto, quando avaliaram, em conjunto, a temperatura axilar, os valores da bilirrubina sérica e a contagem de leucócitos demonstraram uma correlação destes parâmetros com os resultados das culturas. Uma correlação também foi observada neste estudo, no qual detectou-se que os pacientes com dois ou mais fatores preditivos tinham significantemente maior possibilidade de apresentar bactérias na bile e/ou na parede vesicular do que aqueles com menos de dois fatores. Por meio do emprego da análise em conjunto em termos de número de fatores de risco, observou-se um aumento da acurácia (79\%) e do valor preditivo positivo (96\%) em relação a qualquer dos fatores avaliados isoladamente.

Utilizando a análise discriminante multivariada, Farinon et al. ${ }^{17}$ obtiveram um modelo estatístico baseado na temperatura axilar na admissão, na contagem de células brancas, na percentagem de neutrófilos e na concentração de bilirrubinas com sensibilidade de $92 \%$ e especificidade de $100 \%$ em predizer as culturas positivas. Nesta casuística, utilizando-se a análise através da regressão logística múltipla, obteve-se um modelo estatístico baseado na idade e na percentagem de bastonetes que foi capaz de predizer as culturas positivas em $98 \%$ dos doentes estudados. Neste modelo, observou-se que as odds ratio para os fatores idade e percentagem de bastonetes eram, respectivamente, 9,52 e 6,45, indicando que os doentes com idade acima de 55 anos e com percentagem de bastonetes maiores do que $4 \%$ tinham, respectivamente, 9,52 e 6,45 vezes mais chance de apresentar bacteriobilia do que doentes sem estes fatores de risco. Segundo Fletcheretal.1 em um modelo estatístico em que o intervalo de confiança inclui, apenas marginalmente, o valor correspondente ao efeito $(0,95)$ e apresenta, relativamente, grande amplitude de valores, uma diferença significante poderia ter sido encontrada se o estudo tivesse maior amostra. Estas condições foram observadas nos resultados des- 
te modelo, no qual o pequeno número de pacientes em que foi possível avaliar conjuntamente, todos os fatores preditivos encontrados, não permitiu comprovar uma significância estatística.

Nenhum modelo estatístico pode substituir o julgamento lógico e consciente de um cirurgião experiente, quando avaliado o doente individualmente; entretanto, a obtenção de um modelo baseado em variáveis facilmente obtidas no período pré-operatório pode constituir-se em mais uma ferramenta a ser utilizada pelo médico na condução do tratamento e na aplicação mais racional dos antimicrobianos. Apesar de não ter sido possível obter-se um modelo estatisticamente significante por meio da regressão logística, o modelo baseado na idade e na percentagem de bastonetes parece apresentar resultados encorajadores para a realização de um estudo com amostra de maior poder estatístico na medida em que se consegue diagnosticar $98 \%$ dos pacientes com culturas positivas. Com base nos resultados obtidos a partir da análise em conjunto em termos de número de fatores de risco encontrados, também pode-se propor um estudo prospectivo de validação, utilizando antimicrobianos em esquema terapêutico para doentes com dois ou mais fatores de risco, e restringir a sua utilização a um esquema profilático aos pacientes com menos de dois fatores de risco pré-operatórios.

\section{SUMMARY}

\section{Study of Preoperative Risk Fac- tORS for Bactibilia IN Patients With Calculosis Acute Cholecystitis}

ObJECTIVE to determine an association between the preoperative clinical status and the result of bile and gallbladder wall cultures.

Material and Methods. 28 variables regarding history, physical examination and laboratorial assessment in 38 patients with acute calculosis cholecystitis submitted to urgency surgery were prospectively studied during a 19-month period, between November 1995 and May 1997. Cultures for aerobic and anaerobic agents from both the gallbladder wall and the bile were performed, in three different culture media (BACTEC 9240, BHI and HEMOBAC).

RESULTS, bacteria were isolated in at least one culture medium, in $68.2 \%$ of the patients. At univariate analysis, five preoperative factors were identified as predictors of bactibilia: over 55 years of age, a greater than $0.4^{\circ} \mathrm{C}$ difference in the axillary-rectal temperature, a greater than $12.000 \mathrm{cel} / \mathrm{s} / \mathrm{m}^{3}$ blood leukocyte count, a greater than $75 \%$ neutrophil percentage and a greater than $4 \%$ rod neutrophil percentage. Owing to the small sample size, statistical significance of the series could not be noted by logistic regression, although a trend to preoperative determination could be observed in 98\% of the subjects with positive culture, by means of the model based on age and percentage of rod neutrophil. By analyzing predictive factors jointly, it was noted that patients with more than one predictive factor have a significantly greater possibility to yelding positive culture when compared to those with up to one predictive factor for bactibilia.

Conclusions. We concluded that, in patients with acute calculosis cholecystitis, bactibilia may be predicted yet at the preoperative period, by using simple and easily obtained data.

Key Words: Bactibilia. Acute Cholecystitis. Risk Factors.

\section{REFERÊNCIAS BIBLIOGRÁFICAS}

I. Osler W. Modern medicine. Philadelphia. Lea Brothers, 1907. 937p.

2. Prat D. Pathología de las vías biliares: estudio clínico, diagnóstico y tratamiento de las afecctiones de las vías biliares. Buenos Aires, Editorial Medico-Quirurgica, 1946. 862p.

3. Andrews E \& Henry LD. Bacteriology of the normal and diseased gallbladder. Arch Int Med 1935; 56: I 17।-88.

4. Goldman L, Morgan JÁ, Kay J. Acute cholecystitis: correlation of bacteriology and mortality. Gastroenterology 1948; 1 1:318-25.

5. Nielsen ML, Moesgaard F, Justesen T, Scheibel $\mathrm{JH}$, Lindenberg S. Wound sepsis after eletive cholecystectomy: restriction of prophylatic antibiotics to risk groups. Scand J Gastroenterol 1981; 16:937-40

6. Bergan T, Dobloug I, Liavag I. Bacterial isolates in cholecystitis and cholelithiasis. Scand J Gastroenterol 1979; |4:625-31.

7. Chetlin SH \& Elliott DW. Biliary bacteremia. Arch Surg 1972; 102:303-7.

8. Chetlin SH \& Elliott DW. Preoperative antibiotics in biliary surgery. Arch Surg 1973 107:319-23.

9. Keighley MRB, Crapp AR, Flinn R, AlexanderWilliams J. Multivariate analysis of clinical and operative findings associated with biliary sepsis. BrJ Surg 1975; 62:658-9.

10. Reiss R, Eliashiv A, Deutsch AA. Septic complications and bile cultures in 800 consecutives cholecystectomies. World J Surg 1982; 6:195-9.

I I. Lewis RT, Goodall G, Marien B et al. Biliary bacteria, antibiotic use, and wound infection in surgery of the gallbladder and common bile duct. Arch Surg 1987; 122:44-7.

12. Järvinen HJ. Biliary bacteremia at various stages of acute cholecistitis. Acta Chir Scand 1980; 146:427-30.

13. Kobata CM. Contribuição ao estudo dos fatores preditivos de bactibilia em colecistite aguda litiásica. São Paulo, 1990. (Tese - Mestrado Escola Paulista de Medicina).

14. Claesson BEB, Holmlund DEW, Mätzsch TW. Biliary microflora in acute cholecystitis and the clinical implications. Acta Chir Scand 1984 150:229-37.

15. Claesson BEB, Holmlund DEW, Mätzsch TW Microflora of the gallbladder related to duration of acute cholecystitis. Surg Gynecol Obstet 1986; 162:531-5

16. Thompson JE, Bennion RS, Doty JE, Muller EL, Pitt HA. Predictive factors for bactibilia in acute cholecystitis. Arch Surg 1990; 25:26 I-4.

17. Farinon AM, Grande M, Torquati A, Dantini P Multivariate analysis for predicting the presence of bacteria in bile in patients with acute cholecystitis. Eur J Surg 1993; | 59:53 |-4

18. Stone AM, Tucci VJ, Isenberg HD, Wise L. Wound infection: acute versus chronic cholecystitis. Am J Surg 1977; 133:285-8.

19. Siegel S. Estatística não paramétrica (para ciências do comportamento). São Paulo, McGrawHill, 1975. 350p.

20. Armitage P \& Berry G. Statistical methods in medical research. 3.ed. Oxford, Blackwell Science, 1994. 620p.

2 I. Fletcher RH, Fletcher SW, Wagner EH. Clinical epidemiology: the essentials. 2.ed. Baltimore, Willians \& Wilkins, 1988. 246p.

22. Pitt HÁ, Postier RG, Cameron JL. Biliary bacteria: significance and alterations after antibiotic therapy. Arch Surg 1982; 1 17:445-9. 
23. Edlund YA, Mollstedt BO, Ouchterlony Ö. Bacteriological investigation of the biliary system and liver in biliary tract disease correlated to clinical data and microstruture of the gallbladder and liver. Acta Chir Scand 1958; 116: $461-76$.

24. Järvinen HJ, Renkonen OV, Palmu A. Antibiotics in acute cholecystitis. Ann Clin Res | 978; | 0:247-5|.

25. Engström J, Groth CG, Lundh G, Lönnqvist B. Infectious complications after surgery for biliary calculus: the significance of bacteria in the biliary tract. Acta Chir Scand 1972; 138:35761.

26. Watson JF. The role of bacterial infection in acute cholecystitis: a prospective clinical study. Mil Med 1969; 134:41 6-26.

27. Gunn AA. Antibiotics in biliary surgery. Br J Surg 1976; 63:627-30.

28. Sianesi M, Ghirarduzzi A, Percudani M, Dell'anna B. Cholecistectomy for acute chole- cystitis: timing of operation, bacteriologic aspects and postoperative course. Am J Surg 1984; | 48:609- 12 .

29. Tucci GF, Grande M, Torquati A, Percudani M, Rulli F. La profilassi antibiotica nella colecistectomia d'elezione. Policlin Sez Prat 1989; 96:328-34.

30. Fuller DD, Davis TE, Kibsey PC et al. Comparison of BACTEC plus 26 and 27 media with and without fastidious organism supplement with convencional methods for culture of sterile body fluids. J Clin Microbiol 1994; 32:|488-9|.

31. Keighley MRB, Flinn R, Alexander-Williams J. Multivariate analysis of clinical and operative findings associated with biliary sepsis. Br J Surg 1976; 63:528-31.

32. Truedson H, Elmros T, Holm S. The incidence of bacteria in gallbladder bile at acute and elective cholecystectomy. Acta Chir Scand 1983; 149:307-13
33. Csendes A, Brudiles P, Maluenda F et al. Simultaneous bacteriologic assessment of bile from gallbladder and common bile duct in control subjects and patients with gallstones and common duct stones. Arch Surg 1996 131:389-94.

34. Weinstein EC. Acute cholecystitis. J Am Geriatr Soc 1965; 13:760-4

35. Magee RB. \& Macduffee RC. One thousand consecutive cholecystectomies. Arch Surg 1968; 96:858-62

36. Sharp KW. Acute cholecystitis. Surg Clin North Am 1988: 68:269-79.

37. Ahmad MM \& Macon WL. Gangrene of the gallbladder. Am Surg 1983; 49: I I 5- I 58.

Artigo recebido: 15/07/1999

Aceito para publicação: 25/09/2000

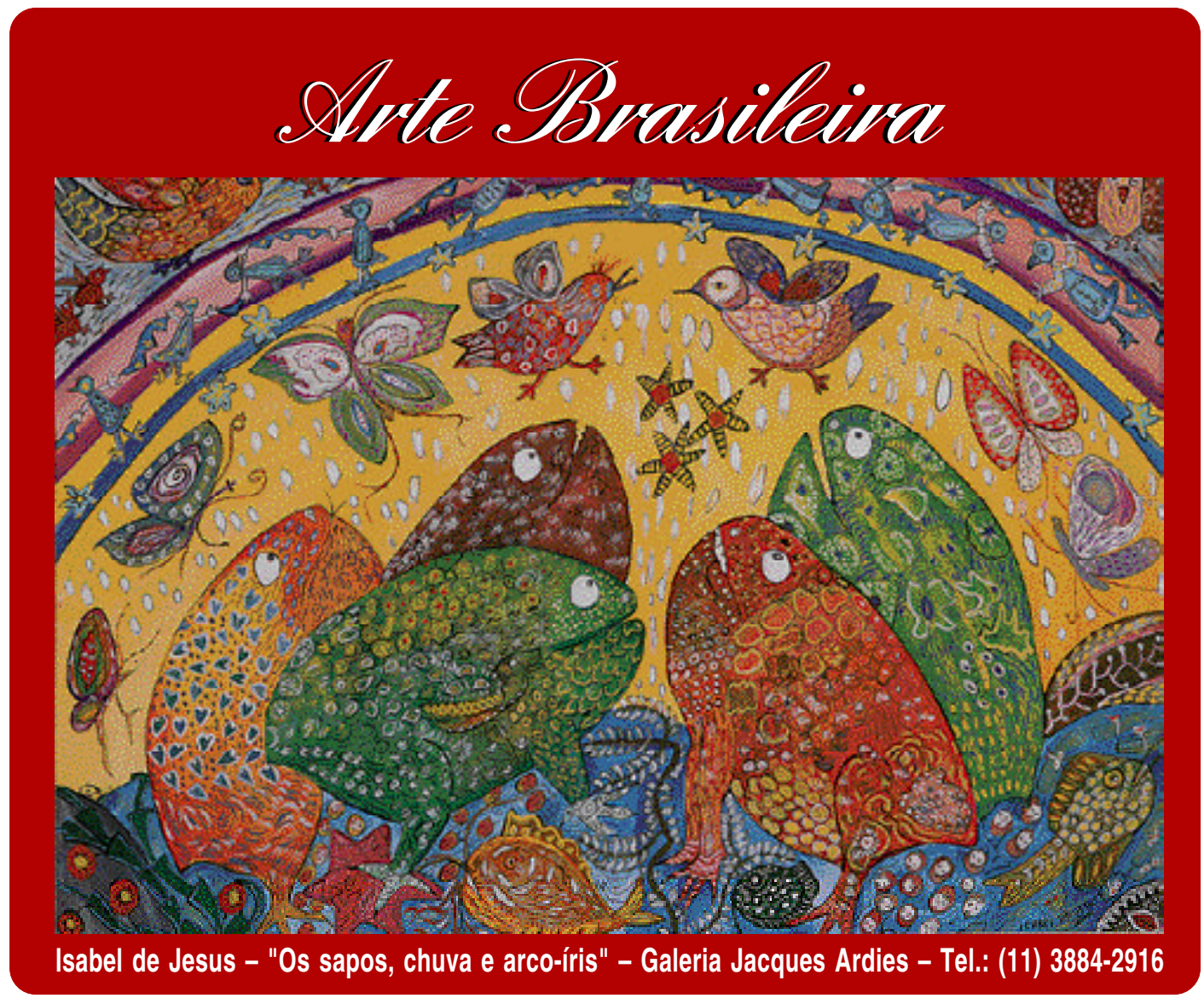

